\title{
EXPERIÊNCIAS DE FAMILIARES DE RECÉM-NASCIDO PREMATURO DURANTE PRIMEIRA ENTRADA NA UNIDADE DE TERAPIA INTENSIVA NEONATAL
}

\author{
Larissa Freitas Cerqueira ${ }^{1}$; Luciano Marques dos Santos ${ }^{2}$; \\ 1. Voluntaria PEVIC/UEFS, Graduando em Enfermagem, Universidade Estadual de Feira de Santana, e-mail: \\ cerqueirafreitaslarissa@gmail.com \\ 2. Orientador, Departamento de Saúde, Universidade Estadual de Feira de Santana, e-mail: lucmarxenfo@yahoo.com.br
}

PALAVRAS CHAVES: Enfermagem familiar; recém-nascidos; prematuros

\section{INTRODUÇÃO}

O parto pré-termo é definido como aquele que ocorre entre a $20^{\mathrm{a}}$ e a $37^{\mathrm{a}}$ semana de gestação ou entre 140 a 257 dias após o primeiro dia da última menstruação (RAMOS; CUMAN, 2009). Segundo a Organização Mundial de Saúde 15 milhões de crianças nascem prematuras, sendo a segunda causa de morte de crianças com menos de 5 anos de idade. Dados desse mesmo estudo mostram que o Brasil está entre os dez países com maiores taxas de partos prematuros (antes de 37 semanas de gestação) (WHO, 2012).

O nascimento de um recém-nascido prematuro (RNPT) demanda assistência de alta complexidade em unidiades de cuidados intensivos ou semi-intensivos neonatais, pois a sua imaturidade pode levar a diversas disfunções orgânicas, que podem impactar em seu desenvolvimento ao longo do tempo, exigindo uma rede de cuidados desde a atenção básica até a rede hospitalar (RAMOS; CUMAN, 2009).

Além das repercussões econômicas e sociais a internação do prematuro na Unidade de Terapia Intensiva Neonatal (UTIN) é uma situação de crise para toda a família, sendo esse um ambiente estranho e assustador, pois o bebê real é diferente do imaginado e o sentimento de culpa atua como fatores inibidores do contato espontâneo entre pais e o bebê. Assim, a hospitalização do recém-nascido prematuro é um momento doloroso e estressante pela sua separação do núcleo familiar (GAIVA; SCOCHI, 2005; ARRUDA; MARCON, 2010).

\section{METODOLOGIA}

Trata-se de um estudo qualitativo, descritivo e exploratório, vinculado à pesquisa multicêntrica "Parto prematuro: estudo dos fatores associados para construção de estratégias de prevenção". Realizado nas Unidades de Terapia Intensiva Neonatal do Hospital Geral Clériston Andrade e Hospital Inácia Pinto dos Santos em Feira de Santana na Bahia.

Participaram deste estudo, familiares de recém-nascidos prematuros hospitalizados nas UTIN dos hospitais anteriormente mencionados. Para a seleção destes entrevistados foram utilizados os seguintes critérios: ter acompanhado a gestação da mãe do RNPT até o parto; ter entrado na UTIN pelo menos duas vezes. Serão excluídos os familiares sem condições mentais e/ou clínicas para responder às perguntas.

As entrevistas aconteceram, por meio da realização de entrevistas semiestruturadas, guiadas por um roteiro contendo as seguintes questões norteadoras: como está sendo para você a experiência de ter entrado na UTIN pela primeira vez? Como você se sentiu neste momento?

As entrevistas foram transcritas na íntegra para compor o corpus empírico da pesquisa, e em seguida lidas profundamente e submetidas à análise de conteúdo temática. 
Este estudo respeitará a Resolução 466/2012 do Conselho Nacional de Saúde, sendo devidamente aprovado pelo Comitê de Ética na Pesquisa da Universidade Federal do Rio Grande através do Parecer de número 134/2013 e no CEP da UEFS através do parecer 643.668.

Foi entregue aos familiares entrevistados o Termo de Consentimento Livre e Esclarecido (TCLE), o documento foi assinado pelo pesquisador (a) e pelo (a) participante, ficando uma cópia uma cópia com o participante e outra com o pesquisador (a).

As informações fornecidas pelos participantes permaneceram confidenciais e o anonimato dos mesmos foi mantido através do uso de nomes (códigos: E01, E02, E03), sendo "E" referente a entrevista e 01,02 , etc., como a quantidade e ordem das entrevistas realizadas.

\section{RESULTADOS}

A análise das entrevistas possibilitou compreender a experiência do familiar durante a hospitalização na UTIN de um RNPT, podendo identificar os sentimentos vivenciados pelos mesmos durante as primeiras visitas na UTIN.

\section{SENDO UMA EXPERIÊNCIA INICIALMENTE ESTRESSANTE}

A análise da primeira categoria evidencia que a experiência de ter um familiar RNPT no contexto do cuidado intensivo neonatal perturba os domínios cognitivos, afetivos e comportamentais da família.

Para melhor compressão do fenômeno, esta categoria contou com cinco subcategorias: "Pensando que a hospitalização na UTIN causaria morte do prematuro"; "Ficando nervoso (a)"; "Tendo choque inicialmente ao ver o prematuro cercado de aparelhos e dispositivos"; "Associando o uso de aparelhos à possibilidade de morte do prematuro"; e "Sentindo-se triste por ver o RN cheio de aparelhos".

1.1 Pensando que a hospitalização na UTIN causaria morte do prematuro

Ao saber que o RNPT estava hospitalizado na UTIN imediatamente a resposta cognitiva do familiar foi pensar na possibilidade de morte do recém-nascido, pois na sua percepção esse espaço hospitalar é destinado a pessoas em estado crítico de saúde com maior possibilidade de óbito. Como é evidenciado na fala abaixo:

[...] Olha para mim UTI já é coisa de morte. Quando falam que fulano foi para UTI a gente fica com medo porque pensa que é caso de morte [...]. (E02)

[...] com medo de perder ele, porque o médico falou que podia esperar qualquer coisa dele, qualquer notícia, fiquei então com medo [...]. (E07)

\subsection{Ficando nervoso (a)}

Os familiares entrevistados sentem-se nervoso (a) diante da incerteza sobre o que encontraria ao entrar na UTIN pela primeira vez.

[...] eu tremia tanto, parecia até que eu não tinha filho (risos) [...] Eu sei lá porque eu tremi, acho que fiquei nervosa, porque eu era a primeira pessoa da família que estava vendo [...]. (E04) 
[...] Quando eu entrei na UTI não tive nem forças pra ficar de junto mais eu fui lá ver [...] tomei foi um susto, eu nunca tinha visto aquilo, toda entubada [...] (E10)

A reação inicial do familiar foi de intenso nervosismo ao entrar pela primeira vez na UTIN deixando sem forças para permanecer por mais tempo neste espaço hospitalar.

[...] eu nem cheguei a ver o bebê direito e já sair na mesma hora [...]. (E11)

O nervosismo do familiar também decorreu da condição clínica do RNPT, a exemplo de sua coloração de pele e de seu tamanho corporal interpretado como condição de total imaturidade orgânica e sem condições de autodefesa que inicialmente promoveu a ausência de contato físico com o mesmo e demandou a saída quase que imediata do familiar da UTIN.

[...] Quando ele nasceu ele estava magrinho, era pequeno demais, nunca vi um bebê pequeno daquele jeito, [...] (E07)

[...] fiquei desesperada, muito nervosa, [...] a cor dela, não estava à cor dela, que ela é "moreninha" [...] ai ela estava toda enroladinha no algodão [...] só o rostinho de fora [...] A primeira vez que eu entrei na UTI, eu não conseguir chegar de junto, tocar [...] pelo tamanho que eu vi ela [...] estava muito sensível, a pele muito fina. (E10)

[...] eu fiquei tão nervosa que nem conseguir chegar perto [...] eu fiquei tão nervosa que escureceu tudo [...]. (E11)

1.3 Tendo choque inicialmente ao ver o prematuro cercado de aparelhos e dispositivos

Ver o RNPT cercado de aparelhos e dispositivos de suporte a vida a exemplo de monitor de dados vitais, ventilação pulmonar mecânica, circuito de pressão positiva continuas em vias aeras, acesso venoso ou sondagens, causou estranhamento para o familiar que inicia a experiência sentindo-se chocada e sem reação diante do que fora visualizado.

[...] eu fiquei assustado, assustado, sei lá, nunca passei por isso. (E01)

[...] Quando entrei na UTI para vê-la eu tomei um choque. De ver a menininha naquele jeitinho. [...] nunca tinha visto menino cheio de aparelho daquele jeito [...] O choque foi de ver naquela situação [...]. (E02)

\subsection{Associando o uso de aparelhos à possibilidade de morte do prematuro}

O familiar associa o uso de aparelhos com a morte do RN diante de sua imaturidade.

[...] Eu nunca tinha visto menino prematuro, nunca tinha visto menino cheio de aparelho daquele jeito eu falei está na mão do senhor! Para mim ela não iria resistir [...] O medo só veio de... eu achei que não iria resistir. [...] Aí eu fiquei com medo, com medo dela morrer [...] Eu achei que aqueles aparelhinhos não iria resistir a vida [...] (E02)

[...] Quando ele nasceu ele estava magrinho, era pequeno demais, nunca vi um bebê pequeno daquele jeito, senti uma tristeza porque achei que ele não ia conseguir viver não, porque já vi um "bucado" de 
bebê de 5,6 meses morrendo então achava que ele não ia conseguir sobreviver não, teve medo de meu filho morrer [...] (E07)

1.5 Sentindo-se triste por ver o RN cheio de aparelhos

A reação do familiar ao perceber a realidade que o RNPT se encontra foi sentir-se triste por pensar que ele está sofrendo e não ter recursos para ajudá-lo a enfrentar a situação.

[...] É muito triste ver ele do jeito que ele estar lá (UTI) (cheio de aparelhos) $[\ldots]($ E07)

[...] o sentimento não foi bom não, porque eu a vi cheia de aparelho [...]. (E08)

[...] é um negócio difícil, ai quando eu vi minha filha eu fiquei com o "coração partido", porque ver aquela criancinha ali [...]. (E09)

O sentimento de tristeza surge também, diante das incertezas sobre a resposta do RNPT mediante a terapêutica clinica utilizada o familiar acompanhante fora informado que não havia previsão da alta hospitalar. Isso mobilizou emocionalmente levando a sentir-se mais triste diante da situação.

[...] mas cheguei lá e o médico falou que ele não tinha data para sair ainda e então teve que esperar mais um pouquinho, sentir tristeza [...]. (E07)

\section{CONCLUSÃO}

A realização desse estudo possibilitou compreender a experiência de familiares de recém-nascido prematuros durante a primeira entrada na UTIN. A experiência de ter um familiar RNPT no contexto da UTIN perturba os domínios cognitivo, afetivos e comportamentais dos familiares.

Inicialmente os familiares tinham a crença de que a UTIN era local de morte e de pessoas em estágio crítico de saúde. Pensavam também que o RNPT é muito vulneral e imaturo, imaginando que estaria sofrendo e que não iria sobreviver. Relataram sentimentos como tristeza, medo e choque diante do uso de aparelhos e dispositivos de suporte à vida, e com isso não conseguiam ficar por muito tempo na UTIN saindo quase de imediato na primeira visita e com isso não estabelecendo um contato com o RNPT.

\section{REFERÊNCIA}

ARRUDA, D. C; MARCON, S. S. Experiência da família ao conviver com sequelas decorrentes da prematuridade do filho. Revista Brasileira de Enfermagem, v. 63, n.4, p. 595-602, 2010.

GAIVA, M. A. M; SCOCHI, C. G. S. A participação da família no cuidado ao prematuro em UTI Neonatal. Revista Brasileira de Enfermagem, v.58, n.4, p 444-448, jul-ago 2005.

RAMOS, H. Â. C; CUMAN, R. K. N. Fatores de risco para prematuridade: pesquisa documental. Escola Anna Nery Revista de Enfermagem, v.13, n.2, p. 297-304, 2009.

WORLD HEALTH ORGANIZATION. Born too soon: the global action report on preterm birth. WHO: Geneva; 2012. 